\title{
Adverse respiratory effects of opioids for chronic breathlessness: learning lessons from chronic pain
}

\author{
To the Editor:
}

Fear of fatal respiratory depression is a major driver limiting opioid prescription for persistent breathlessness in chronic obstructive pulmonary disease (COPD) [1-6], but is this fear warranted? In a recent systematic review and meta-analysis, VERBERKT et al. [7] did not detect significant or clinically relevant respiratory adverse events associated with opioid treatment for chronic breathlessness in COPD. Rather, they concluded that "clinicians' fears of respiratory obtundation with low-dose opioids seem to be unfounded". Here, we critically evaluate these conclusions.

Firstly, all included studies utilised resting measures of respiratory rate, carbon dioxide or oxygen to detect respiratory compromise. These are poor measures of respiratory depression, due to complex interactions between chemoreception, $\mathrm{CO}_{2}$ excretion and wakefulness (figure 1). Instead, direct measurement of chemoreflex responses is needed to enable more accurate measurement of respiratory depression [8]. Additionally, resting measures do not encapsulate the important effect that opioids may have on breathing during sleep [9], including central sleep apnoea, hypoventilation and oxygen desaturation. Nocturnal hypoxaemia is common in COPD [10] and is likely to be exacerbated by opioids. As such, polysomnography or overnight pulse oximetry would better assess respiratory risk.

Secondly, the data reviewed were powered for efficacy rather than adverse events. The median sample size of the studies considered was just 15.5 patients, and they were thus underpowered to detect true adverse event rates. While the authors state "Data about respiratory adverse effects of opioids are limited and conflicting", their manuscript pointedly ignores the vast literature on the respiratory effects of opioids from other fields of research.

Therefore, we would like to highlight that the world of opioid analgesia has, in fact, been here before. The parallels are marked between the historic arguments used to justify more opioid usage in the treatment of chronic pain and present arguments for their use in chronic breathlessness. In both cases, there is an implication that overcautious clinicians with undue concern are withholding an effective treatment that could relieve a patient's distress. In each case, conclusions have been drawn from palliative care, where the ethical drive is to relieve suffering above all else. Of particular note, VERBERKT et al. [7] state "Patients are willing to consider opioid treatment for chronic breathlessness, despite the occurrence of adverse effects [...] However, physicians remain reluctant to prescribe opioids for chronic breathlessness, because of fear of adverse clinical outcomes".

With remarkable similarity, the 1986 paper by Portenoy and Foley [11] on opioid use in chronic noncancer pain commented "opioid maintenance therapy can be a safe, salutary and more humane alternative to [other] options [...] Enthusiasm for chronic therapy, however, has traditionally been tempered by the $[. .$.$] often-stated risk of psychological dependence after sustained exposure to these drugs."$

Following this, in 1997, the American Academy of Pain Medicine published a promotional consensus statement titled "The use of opioids for the treatment of chronic pain" [12]. As a consequence, opioid prescription for nonmalignant chronic pain skyrocketed, paralleled by a rapid increase in opioid deaths [13]. However, we now know that tolerance to analgesia develops more profoundly than the tolerance to respiratory depression $[14,15]$ and thus, over time, the risks of adverse events increase. To further

@ERSpublications

Chronic breathlessness: beware adverse effects of opioids; no new evidence for safety or efficacy in long-term use http://ow.ly/vXWv30hVcMS

Cite this article as: Pattinson KTS, Rowland MJ, Nickol AH, et al. Adverse respiratory effects of opioids for chronic breathlessness: learning lessons from chronic pain. Eur Respir J 2018; 51: 1702531 [https://doi. org/10.1183/13993003.02531-2017]. 


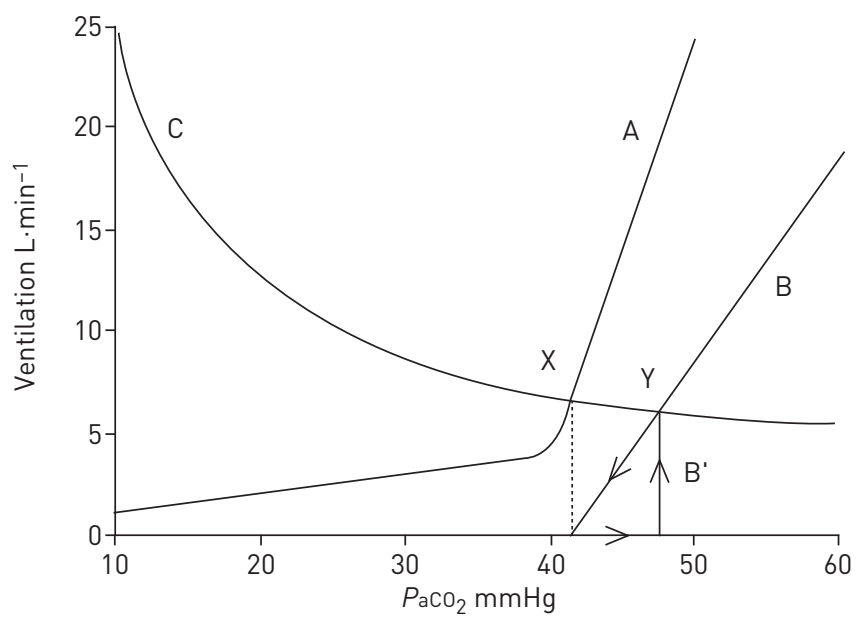

FIGURE 1 This diagram demonstrates how opiates can induce apnoea at the same arterial carbon dioxide tension $\left(\mathrm{PaCO}_{2}\right)$ as before opioid administration (dotted line) and also demonstrates that significant reductions in the hypercapnic ventilatory response (HCVR) only cause small changes in steady-state $P_{a C O}$. Curve A represents the normal ventilatory response to $\mathrm{CO}_{2}$ in an awake individual, demonstrating that ventilation is maintained at very low $\mathrm{PaCO}_{2}$ levels and that apnoea does not occur. Line B represents a $50 \%$ depression of the HCVR caused by opioid administration. A notable difference between curve $A$ and line $B$ is that in $B$, apnoea can occur. Note also that in this case, $\mathrm{PaCO}_{2}$ must rise to steady-state values (i.e. along the $x$-axis) for breathing to recommence (line $\mathrm{B}^{\prime}$ ). Curve $\mathrm{C}$ represents the $\mathrm{CO}_{2}$ excretion hyperbola and demonstrates how changes in ventilation affect $\mathrm{PaCO}_{2}$. Point $\mathrm{X}$ represents the awake state and point $\mathrm{Y}$ represents opioid-depressed breathing. Despite a $50 \%$ depression of the $\mathrm{HCVR}$, the $\mathrm{CO}_{2}$ changes only relatively modestly, illustrating the limited utility of single measurements of $\mathrm{CO}_{2}$ in assessing respiratory depression. Reproduced and modified from [27] with permission from the publisher.

compound matters, patients with higher levels of anxiety and depression (ubiquitous in both chronic pain and chronic breathlessness) are more likely to respond poorly to opioid therapy, are more likely to require dose escalation and have more difficulties weaning from opioid therapy [16-18]: the perfect storm for increased respiratory adverse events.

There are indeed important differences between patients with chronic pain and those with COPD. Despite increased neural motor output driving respiratory muscles in COPD [19], effective ventilatory responses to hypercapnia (increased arterial $\mathrm{CO}_{2}$ ) and hypoxia are blunted due to neuromechanical dissociation [20, 21]. Therefore, opioids may even further obtund ventilatory responses and exacerbate hypoventilation in these individuals. Although we do not know of any work that has studied this in detail, it is interesting to note that COPD is, in fact, a known risk factor for opioid-induced respiratory depression following surgery [22].

Finally, with all of this said, we must consider whether prescribing maintenance opioids for chronic breathlessness is even worth the risk. Although opioids are efficacious for the treatment of acute pain, there is little evidence that they are helpful for chronic pain beyond 3 months [23]. Longer-term studies have found worsened outcomes in terms of quality of life, depression and pain, and significant increases in all-cause mortality [24]. While no studies exist beyond 3 months in breathlessness, based on the history books, we might be able to hazard a guess as to the likely outcomes.

So where do we go from here? Large numbers of people with COPD already receive opioids for pain relief [25] and thus provide an ideal population in whom we can better understand the pharmacodynamics of opioids. Basic physiological studies could help to understand how opioids influence respiratory control in COPD, while sleep studies are needed to investigate whether opioids cause (or worsen) sleep disordered breathing more prominently in COPD than health. Such work would help avoid subjecting large numbers of opioid-naïve people with COPD to novel prospective trials powered for adverse events. Based upon current knowledge, we would even question the ethics of performing such a trial in a population who already have compromised respiration.

And thus, to answer our original question, we believe that fear of adverse respiratory events is still warranted. The opioid epidemic surrounding the over-prescription, drug misuse and the rising tide of deaths [17], has proved a chastening experience for pain physicians. It would be negligent for the respiratory community to ignore those lessons. As noted by Mark Sullivan, a professor of psychiatry and pain in Seattle [26], "The US has conducted an experiment of population-wide treatment of chronic pain with long-term opioid therapy. The benefits have been hard to demonstrate, but the harms are now well demonstrated." 
Kyle T.S. Pattinson ${ }^{1,2}$, Matthew J. Rowland ${ }^{1,2}$, Annabel H. Nickol $^{3}$ and Jane Quinlan ${ }^{1,2}$

${ }^{1}$ Nuffield Dept of Clinical Neurosciences, University of Oxford, Oxford, UK. ${ }^{2}$ Nuffield Dept of Anaesthetics, Oxford University Hospitals NHS Foundation Trust, Oxford, UK. ${ }^{3}$ Oxford Centre for Respiratory Medicine, Oxford University Hospitals NHS Foundation Trust, Oxford, UK.

Correspondence: Kyle T.S. Pattinson, Nuffield Dept of Clinical Neurosciences, University of Oxford, John Radcliffe Hospital, Oxford, OX3 9BT, UK. E-mail: kyle.pattinson@nda.ox.ac.uk

Received: Dec 062017 | Accepted after revision: Dec 212017

Conflict of interest: K.T. Pattinson reports receiving personal fees from Nektar Pharmaceuticals outside the submitted work. J. Quinlan is a core member of the Opioid Painkiller Dependence Alliance. This is a voluntary organisation and she has received no financial or other benefits from this.

\section{References}

1 Johnson MJ, Yorke J, Hansen-Flaschen J, et al. Breathlessness despite optimal pathophysiological treatment: on the relevance of being chronic. Eur Respir J 2017; 50: 1701297.

2 Johnson MJ, Yorke J, Hansen-Flaschen J, et al. Towards an expert consensus to delineate a clinical syndrome of chronic breathlessness. Eur Respir J 2017; 49: 1602277.

3 Calverley PMA. Breathlessness despite optimal pathophysiological treatment: on the relevance of being chronic. Eur Respir J 2017; 50: 1701376.

$4 \quad$ Calverley PMA. Chronic breathlessness: symptom or syndrome? Eur Respir J 2017; 49: 1700366

5 Faull OK, Marlow L, Finnegan SL, et al. Chronic breathlessness: re-thinking the symptom. Eur Respir J 2018; 51: 1702238 .

6 Macnaughton J, Oxley R, Rose A, et al. Chronic breathlessness: re-thinking the symptom. Eur Respir J 2018; 51 1702331.

7 Verberkt CA, van den Beuken-van Everdingen MHJ, Schols JMGA, et al. Respiratory adverse effects of opioids for breathlessness: a systematic review and meta-analysis. Eur Respir J 2017; 50: 1701153.

8 Pattinson KT. Opioids and the control of respiration. Br J Anaesth 2008; 100: 747-758.

9 Webster LR, Choi Y, Desai H, et al. Sleep-disordered breathing and chronic opioid therapy. Pain Med 2008; 9: 425-432.

10 Little SA, Elkholy MM, Chalmers GW, et al. Predictors of nocturnal oxygen desaturation in patients with COPD. Respir Med 1999; 93: 202-207.

11 Portenoy RK, Foley KM. Chronic use of opioid analgesics in non-malignant pain: report of 38 cases. Pain 1986; 25: $171-186$.

12 The use of opioids for the treatment of chronic pain. A consensus statement from the American Academy of Pain Medicine and the American Pain Society. Clin J Pain 1997; 13: 6-8.

13 Okie S. A flood of opioids, a rising tide of deaths. N Engl J Med 2010; 363: 1981-1985.

14 Teichtahl $\mathrm{H}$, Wang $\mathrm{D}$, Cunnington $\mathrm{D}$, et al. Ventilatory responses to hypoxia and hypercapnia in stable methadone maintenance treatment patients. Chest 2005; 128: 1339-1347.

15 Paronis CA, Woods JH. Ventilation in morphine-maintained rhesus monkeys. II: Tolerance to the antinociceptive but not the ventilatory effects of morphine. J Pharmacol Exp Ther 1997; 282: 355-362.

16 Sullivan MD. Why does depression promote long-term opioid use? Pain 2016; 157: 2395-2396.

17 Wasan AD, Davar G, Jamison R. The association between negative affect and opioid analgesia in patients with discogenic low back pain. Pain 2005; 117: 450-461.

18 Edwards RR, Dolman AJ, Michna E, et al. Changes in pain sensitivity and pain modulation during oral opioid treatment: the impact of negative affect. Pain Med 2016; 17: 1882-1891.

19 Jolley CJ, Luo YM, Steier J, et al. Neural respiratory drive in healthy subjects and in COPD. Eur Respir J 2009; 33: 289-297.

20 Jacono FJ. Control of ventilation in COPD and lung injury. Respir Physiol Neurobiol 2013; 189: 371-376.

21 Gelb AF, Klein E, Schiffman P, et al. Ventilatory response and drive in acute and chronic obstructive pulmonary disease. Am Rev Respir Dis 1977; 116: 9-16.

22 Gupta K, Prasad A, Nagappa M, et al. Risk factors for opioid-induced respiratory depression and failure to rescue: a review. Curr Opin Anaesthesiol 2018; 31: 110-119.

23 Chou R, Turner JA, Devine EB, et al. The effectiveness and risks of long-term opioid therapy for chronic pain: a systematic review for a National Institutes of Health Pathways to Prevention Workshop. Ann Intern Med 2015; 162: 276-286.

24 Ray WA, Chung CP, Murray KT, et al. Prescription of long-acting opioids and mortality in patients with chronic noncancer pain. JAMA 2016; 315: 2415-2423.

25 Vozoris NT, Wang X, Fischer HD, et al. Incident opioid drug use and adverse respiratory outcomes among older adults with COPD. Eur Respir J 2016; 48: 683-693.

26 Sullivan MD, Howe CQ. Opioid therapy for chronic pain in the US: promises and perils. Pain 2013; 154: Suppl. 1 , S94-S100.

27 Gross JB. When you breathe IN you inspire, when you DON'T breathe, you...expire: new insights regarding opioid-induced ventilatory depression. Anesthesiology 2003; 99: 767-837. 